\title{
The Party's Inspection and the Analysis of Effectiveness of Internal Control in Public Colleges and Universities
}

\author{
Xiaomin Huang \\ No. 200, Xiyuangong Road, Shangjie Town, Minhou County, Fuzhou City, Fujian Prov. China
}

1115@mju.edu.cn

Keywords: The Party's inspection; Public Colleges and Universities; Internal Control; Effectiveness.

\begin{abstract}
As an important supervision mechanism to strengthen the restriction of power operation, the Party's inspection work has evolved into an institutional arrangement. This paper studies the inspection summaries of public colleges and universities by inspection groups higher than provincial level, analyzes the main problems leading to internal control failure in these schools and the effect of "looking back", and puts forward suggestions for the construction of the effectiveness of internal control in public colleges and universities.
\end{abstract}

\section{Problem Raising and Sample Selection}

The inspection work is a weapon to strictly manage the Party and is an important means of achieving internal supervision of the Party. Since the 18th CPC National Congress, the Party Central Committee has clearly taken the building of a clean government within the Party and the anti-corruption campaign as the center of inspection. While strengthening the inspection work, the 4th Plenary Session of the 18th CPC Central Committee also explicitly proposed to promote the internal control of administrative institutions to restrict the internal power of the government. Ministry of Finance issued a series of internal control systems for public departments. By making explicit the basic content of internal control, specific tasks, implementation steps, reporting requirements and deadlines for implementation, the internal control of administrative institutions should be promoted from economic activities to power operations and all business areas. Although Ministry of Finance respectively issued Guiding Opinions on Comprehensively Promoting the Internal Control Construction of Administrative Institutions and Notice on Carrying out the Basic Evaluation of the Internal Control of Administrative Institutions in 2016, all units vary in their construction and operation of internal control, and there is no relevant data on internal control evaluation. Therefore, this paper takes the information related to internal control, disclosed during the inspection process, by the inspection groups and the inspected units as the research object, and analyzes the effectiveness of internal control in public colleges and universities, with feedback from 10-round central inspection of the Party in 2013-2016 and its implementation of rectification as the research sample. It also explores how to effectively promote the realization path of the internal control of units with the help of combined forces.

This paper selects the most studied object of the corresponding units' inspection report files of the 10 rounds of inspection, which have been completed now and carried out by inspection groups higher than provincial level since the 18th CPC National Congress. The contents related to internal control in the inspection reports are manually downloaded, organized and collected. 
Table 1 Sample Statistics of Inspection Groups Higher than Provincial Level since the 18th CPC National Congress

\begin{tabular}{|c|c|c|}
\hline Inspection Year & Number of Schools Inspected & Ratio \\
\hline 2013 & 17 & $17 \%$ \\
\hline 2014 & 25 & $25 \%$ \\
\hline 2015 & 21 & $21 \%$ \\
\hline 2016 & 37 & $37 \%$ \\
\hline Total & 100 & $100 \%$ \\
\hline
\end{tabular}

\section{Main Problems Leading to Internal Control Failure in Public Colleges and Universities in the Inspection Reports}

Insufficient Understanding of Internal Control Subjects. The leaders of public colleges and universities lack a comprehensive and correct understanding. These leaders include all members of school-level administration, especially the secretary and principal, the main leaders in charge of the schools. Their understanding of internal control would inevitably exert a profound demonstration effect upon the schools. However, the majority of the school leaders lack correct, systematic and comprehensive understanding of internal control, which is mainly reflected in the following aspects: First, they do not understand what internal control is, which leads to their inaccurate and incomplete understanding of the internal control in colleges and universities. Second, they only have one-sided understanding of internal control. For instance, they consider internal control to be the work of financial and auditing departments, simply equating financial budget management system with internal accounting control system and ignoring the fact that internal control is a system that requires environmental construction, effective implementation, and full participation and the reality that all internal departments are internal control subjects. The full-course internal control which is integral and comprehensive can be only constituted by all departments' participation. Third, the internal control in these schools tends to be formalized, randomized and simplified. That is to say, though the internal control system has been established, its execution appears to be arbitrarily implemented: It is operated selectively. The system sometimes works, but sometimes not; sometimes tightened, but sometimes loosened. And it is randomly implemented in different places because of different people and things. Fourth, the internal control mechanism co-managed by the Party and government has not been established, and there is no corporate governance structure of modern colleges and universities. Therefore, the responsibility of internal control can not be really performed. As a result, the internal control in these schools is rather weak in terms of system, entirety and integrality

Lack of Due Standards for Internal Control. At present, the internal control in public colleges and universities lacks corresponding standards, which makes the schools' internal control evaluation ungrounded ${ }^{[1]}$. The main representations are as follows: First, there are many qualitative standards, which are easy to fall into the dilemma of unconvincing subjective judgments. Second, much emphasis is placed on expenditure activities, but business process control is neglected. Third, there are no definite standards beforehand, and no evaluation afterwards either. Fourth, there are too few quantitative standards, which is currently the biggest problem in the internal control in colleges and universities. At the same time, there are also too few quantitative indicators for the assessments of all departments, resulting in various opinions that are difficult to evaluate and contradictions that keep arising.

Unscientific Financial Budget Control. Although the budgeting should be led by finance department and play an important role, budgeting is related to all departments. The scientific degree of budgeting can be only increased through the active participation by all the departments. However, the actual situation is not entirely the same. In preparing their budgets, some schools let their finance departments replace other departments, use subjective judgments instead of objective reality and leadership opinions instead of interdepartmental communication, resulting in a lack of 
objective basis for the budget preparation and frequent changes during implementation. Thus, the budget control can not play its role basically. Moreover, most colleges and universities focus on development and neglect risks. Operating with heavy financial liabilities and deficits, the schools are severely weakened in their budgetary constraints, making their finances face the risk of overall imbalance. Meanwhile, since there is no system set up for budget implementation negotiation, tracking, analysis and evaluation, it is impossible to make detailed, authentic, accurate, comprehensive and complete evaluations of all departments' expenditures.

Unreasonable Internal Control Process. First, the review and approval process for expenditures is reversed. The process can be carried out in two ways: First, financial department reviews before school leaders approve. Second, the school leaders approve before financial department reviews. In theory, the first should be adopted. However, in real situation, due to the influences of university management concepts, personnel quality, desire for leadership, etc., it is very difficult to implement the first. Then, the control process is not comprehensive. The process includes three links: pre-existing control, in-process control, and post control. The pre-existing control, being the first link, lack control basis beforehand. That is to say, many plans, programs, expenditures, and project implementation effects have not been fully demonstrated in advance actually. Since there's lack of evaluation criteria, the objectives of in-process control cannot be achieved. It is difficult to evaluate the implementation of the budget, so the role of post control cannot play. Third, the internal control process is not transparent. In large fund management, some colleges and universities have insufficient collective discussion, and the main leaders have the final say; Some have not sufficient preparations beforehand though they have gone through meeting discussion. The materials needed are not complete, the conclusions are not clear, and there are no meeting records or only incomplete records. Thus, the decision-making process is made non-transparent, non-standard, and non-rigorous.

Weak Risk Awareness of Internal Control. In the operating management of public colleges and universities, risks do exist, such as the legal risks caused by violation of laws and regulations, contracts signed carelessly, etc.; those brought about by the low quality of teaching, the transferred school-run industry, the low efficiency of running schools, the declining competition among peer schools, the shortage of teachers and others; the financial risks generated by arbitrary capital budgets, uncertain incomes and expenditures, high debts, etc. The risks can be ubiquitous. However, college and university leaders believe that public higher institutions are state-owned and face no risks. Even if there are risks, the state will ultimately bear them. Therefore, the leaders generally do not pay attention to the risks that actually exist. Some colleges and universities do not analyze the risks arising from the excessive expansion of large bank loans, which gives rise to a large number of bank loans and makes colleges and universities heavily in debt. The loan interests alone of some colleges and universities account for $20 \%$ of the schools' annual incomes, or even $40 \%$ to $80 \%$. The consequences of this practice without risk analysis and evaluation are very serious. Lastly, most colleges and universities do not establish a risk control system.

\section{Analysis of the Effects of "Looking Back" on the Internal Construction in Public Colleges and Universities}

In order to enhance the supervision and examination of inspection work, the central inspection begins to adopt a "looking back" approach to re-inspect the effectiveness of the rectification of the public colleges and universities that have been inspected. As of the tenth round of inspection, a total of 18 schools have carried out "looking back" and shared feedback on the implementation of rectification. The results of the two inspections before and after "looking back" are compared. The analysis is shown in Table 2: 
Table 2 Effect Analysis of Internal Control Construction of "Looking Back"

\begin{tabular}{|l|l|l|l|l|l|l|}
\hline & ICQUORG & ICQUOBUS & ICQU & ICADORG & ICADBUS & ICAD \\
\hline $\begin{array}{l}\text { Result of First-round } \\
\text { Inspection }\end{array}$ & 1.625 & 2.75 & 4.75 & 2.125 & 1.5 & 4.625 \\
\hline $\begin{array}{l}\text { Result of "looking back" } \\
\text { Inspection }\end{array}$ & 2.889 & 1.111 & 4.556 & 2.889 & 0.778 & 4.000 \\
\hline Difference Contrast & 1.264 & -1.639 & -0.194 & 0.764 & -0.722 & -0.625 \\
\hline
\end{tabular}

It can be seen from the above table that the inspection work has indeed played a positive role in promoting the implementation of internal control in public colleges and universities and has achieved tangible results. This paper believes that the degree of attention paid to the problems found in the inspection work further promotes the internal control construction and its effectiveness of public colleges and universities.

\section{Suggestions on Strengthening the Effectiveness of Internal Control in Public Colleges and Universities}

Scientific criteria for determining the effectiveness of internal control. The standards for internal control effectiveness always guide the behaviors of internal control in colleges and universities. Forming a multi-level system, the measurement standards for the effectiveness involve all aspects and many links of colleges and universities. The specific standards should include measurements in six aspects: the strategic objectives of the schools, compliance (rules, systems) objectives, asset security objectives, risk control objectives, information authenticity objectives, and performance evaluation objectives. ${ }^{[2]}$ The internal control in colleges and universities should not stay at the stages of error prevention, error checking and error correction. It should pursue a higher management level and strengthen the schools' performance management to ensure the achievement of performance goals.

Consolidation of the Guarantee of Internal Control Effectiveness. To ensure the effectiveness of internal control, the schools should first clarify the responsibility subjects of their leaders. The attitude of the leaders determines the effectiveness of internal control. It can achieve the desired results only if the leaders attach importance to internal control. Second, the schools should improve the internal control responsibility system of colleges and universities, and clarify the duties, authorities, procedures, codes of conduct, and rewards and penalties for all the top-down personnel in the whole course including secretary, principal, deputy secretary, deputy principal, directors and vice directors of various departments (secondary colleges), section chiefs and chief members. There are responsibility personnel at each level to form a responsibility chain of internal control. Third, business training and professional ethics education are strengthened. The business training and professional ethics education of faculty and staff are strengthened and the spirits of observing laws and regulations, being honest in performing one's official duties, and being passionate in one's job are established. The assessments of faculty members are also established and improved to make them accept constraints willingly, which transforms into conscious behavior of internal control.

Enhancement of Risk Control. First, the schools should establish risk awareness and should learn to identify and control risks. They should establish risk prevention and control systems, such as the systems of financing risk prevention and control, investment risk evaluation and control, contract risk control, etc. They should improve the risk control system. To improve the risk control system, the schools should first establish a financial risk prediction mechanism to warn of possible risks. The greatest risk representations of colleges and universities' finance are debt crisis caused by their failure to pay the due debts and reckless and irresponsible investment in assets and equipments without considering usage effects and economic benefits.

Second, the schools should standardize post responsibility, prevent liability risks, and implement a layer-by-layer accountability system so that managers at all levels can consciously pay attention to internal management control. When handling all economic activities, they form a 
vertical control responsibility of top-down multiple levels of audit (review). The chain also forms a horizontal control responsibility of multi-position (department). The departments supervise each other, yet remain independent units.

Third, the schools should strengthen financial internal control and improve their ability to identify false and inappropriate activities that may cause major defects or even crimes. The greatest factors determining potential risks of financial internal control in colleges and universities are their financial staff's business familiarity and discernment, professional ethics, sense of dedication and responsibility, etc.

Finally, the schools have to improve their ability to supervise internal audit. The primary role of internal auditors is supervisors, but to play the most effective role in internal control, it is not enough for them to assume the role of supervisors alone. Therefore, internal auditors should also be advocators, coordinators, message senders, demonstrators, waiters, advisors and participants. Relevant departments and individuals should be made to recognize that internal auditors are helping to improve their departments and their own business levels. These roles are not unitary, but integrated. Only by truly taking on these roles can auditors play the most effective functions. At the same time, internal audit should realize its mode transformation, transferring from passive audit to active audit. The schools should focus on carrying out tracking audit and performance audit to measure the economy, effects and profits of business work.

\section{References}

[1] Qingfeng Gao: submitted to Journal of Friends of Accounting ( 2013)

[2] Zhengbing Liu: submitted to Journal of Soochow University (Philosophy \& Social Science Edition) (2013)

[3] Hong Guo: submitted to Journal of Communication of Finance and Accounting(Financing Version)(2006)

[4] Shanqing Zhao : submitted to Journal of Finance and Accounting Monthly(2014)

[5] Information http://www.moe.gov.cn 